\title{
Choosing Wisely Canada: Canadian Fertility and Andrology Society's List of Top Items Physicians and Patients Should Question in Fertility Medicine
}

\section{Claire Jones}

University of Toronto

\section{Leslie Hawkins}

University of Toronto

Catherine Leah Friedman ( $\nabla$ catherine.friedman@medportal.ca )

McMaster University https://orcid.org/0000-0001-5236-527X

Jason Hitkari

University of British Columbia

\section{Eileen McMahon}

Sinai Health System, 700 - 250 Dundas Street West Toronto

\section{Karen Born}

Dalla School of Public Health, University of Toronto

\section{Research Article}

Keywords: Ethics, Recurrent Miscarriage, Gonadotrophins, Infertility, IVF/ICSI Outcome, Gene Mutations, DNA Damage, Cost Effectiveness, Assisted Hatching

Posted Date: December 9th, 2021

DOl: https://doi.org/10.21203/rs.3.rs-1112308/v1

License: (c) (i) This work is licensed under a Creative Commons Attribution 4.0 International License.

Read Full License

Version of Record: A version of this preprint was published at Archives of Gynecology and Obstetrics on March 12th, 2022. See the published version at https://doi.org/10.1007/s00404-022-06453-z. 


\section{Abstract}

Purpose: To create a Choosing Wisely Canada list of the top 5 diagnostic and therapeutic interventions that should be questioned in Reproductive Endocrinology and Infertility in Canada.

Methods: The Canadian Fertility and Andrology Society (CFAS) National Working Group developed an initial list of recommendations of diagnostic and therapeutic interventions that are commonly used, but are not supported by evidence, and could expose patients to unnecessary harm. These were chosen based on their prevalence, cost, potential for harm, and quality of supporting evidence. A modified Delphi consensus was used over 5 rounds to generate ideas, review supporting evidence, assess clinical relevance, estimate recommendation impact and narrow the recommendations list to 5 items.

Results: Fifty unique ideas were first proposed by the working group, and after 5 rounds including a survey of Canadian Fertility and Andrology Society (CFAS) members, the final list of recommendations was created, including topics related to unnecessary investigations and interventions for patients with infertility and recurrent pregnancy loss, and those undergoing IVF. In this article, we describe not only the Delphi process used to determine the list, but also provide a summary of the evidence behind each of the final recommendations.

Conclusions: The list of 5 recommendations highlights opportunities to initiate conversations between clinicians and patients about the risks, benefits, harms and costs of unnecessary fertility treatments and procedures in a Canadian context.

\section{Introduction}

Fertility treatments can be expensive and difficult to access for many people [1]. Despite Canada's public health care system, there is a patchwork of coverage for fertility care with significant variation from province to province [2]. Given the absence of universal public funding for fertility services, there is potential for conflicts of interest when physicians or clinics stand to profit from ordering tests or interventions; this is compounded when there is limited evidence supporting a benefit to patients [3]. Furthermore, it is well established that patients undergoing fertility treatments can experience anxiety and stress, and may be more willing to undertake unproven and costly tests, treatments, and procedures to achieve successful pregnancies [3]. Beyond costs, these treatments can cause harms including side effects, time away from work and home, and mental health impacts [2].

Despite the availability of fertility treatment add-ons, there is limited evidence for many of the commonly used diagnostic and therapeutic interventions in fertility medicine [4]. Choosing Wisely is an international clinician-led movement that aims to bring awareness to such unnecessary and unproven investigations and treatments across all fields of healthcare, including Reproductive Endocrinology and Infertility (REI) [5]. With the support of over 50 Canadian clinician societies, Choosing Wisely Canada (CWC) has released more than 300 recommendations of tests and treatments that are commonly used in a specialty, but are not supported by evidence, and could expose patients to unnecessary harm [6]. While the American 
Society for Reproductive Medicine (ASRM) has released 10 Choosing Wisely recommendations for REI, their list focused almost exclusively on evaluation of infertility rather than treatment of infertility [7]. In addition, as there was no list of recommendations specific to the Canadian context, our objective was to create a CWC recommendations list on behalf of the Canadian Fertility and Andrology Society (CFAS) of the top 5 diagnostic and therapeutic interventions in REl that should be questioned in clinical practice. In this article we describe our multistage Delphi methodology used to derive the list, as well as summarize the evidence supporting each recommendation.

\section{Methodology: How The List Was Created}

The CFAS commissioned a national working group to create the CWC recommendations list. Eleven volunteer Canadian clinicians with diverse expertise in REI were recruited to participate, including $7 \mathrm{REI}$ specialist physicians, 2 embryologists, 1 nurse practitioner, and 1 general gynecologist. Team members had variable years of experience, setting of practice, and research expertise. The Delphi consensus is an approach used to achieve convergence from a diverse group of experts on complex, real-world issues, and has been used for development of other Choosing Wisely lists, including CWC's obstetrics and gynecology list of 10 recommendations $[8,9]$. We used a modified Delphi consensus approach consisting of 5 rounds to generate ideas, review best available research evidence, assess clinical relevance, estimate impact, and narrow the recommendations to a final list of 5 (Figure 1).

Round 1 of the Delphi process solicited ideas from working group members based on their expertise, omitting any duplicate suggestions. In round 2, these proposed items were evaluated via an online anonymous survey administered to the working group, asking each member to rate items on a 5-point Likert scale (from 1, strongly disagree, to 5, strongly agree) based on degree of agreement with the item's inclusion in the list. An item was carried forward if at least 1 of 4 criteria were met: complete consensus was achieved (all members answered agree or strongly agree), all responses were neutral (neither agree or disagree) or positive (agree or strongly agree), mean Likert scores were greater than or equal to 4.0, or the item was on the ASRM Choosing Wisely list [7].

Round 3 consisted of evaluation of the list by the working group in an in-person meeting held in Toronto, Ontario. Prior to the meeting, literature reviews were conducted to ensure that relevant evidence was applied to each item. During the meeting, each item was discussed in the context of the literature, and at the conclusion of the meeting, an anonymous survey was again administered. Using the aforementioned criteria, items carried forward to round 4 were then included in an online survey distributed to the national CFAS membership via email. This survey asked respondents to evaluate each item in several domains: degree of agreement with including the recommendation (i.e. very important - include, moderately important - consider inclusion, not important - do not include), prevalence of the issue, cost of the intervention, potential for harm, and finally a binary option for each item asking participants whether or not they felt the recommendation should be included in the top 5 list. 
Data analysis was completed using Microsoft Excel 2016 software. Descriptive statistics were used to calculate means and proportions. Content agreement was determined by the sum of "very important" and "moderately important" responses for each item. Prevalence, cost, and potential for harm responses were combined into an aggregate score for each item, weighing each domain equally. Round 5 involved using this information in addition to guidance and feedback from the CFAS Board of Directors to compose the final list, which was approved by the working group, the CFAS Board of Directors, and CWC before publication (Table 3).

\section{Results Of The Delphi Consensus Process}

In round 1 , the working group generated 50 unique ideas of items in fertility practice that are potentially unnecessary. Round 2 narrowed this to 28 items, round 3 to 14 items, and round 4 to 13 items, which were then evaluated in the national CFAS membership survey for the final round (Figure 1). One-hundredand-twenty-nine CFAS members responded to this survey, which was distributed to approximately 600 members who agreed to be contacted by email correspondence, achieving a $21.5 \%$ response rate (Table 1). Results of the survey were reviewed by the working group, who created the final recommendations list based on those with the 5 highest content agreement scores, and the 5 highest aggregate scores for prevalence, cost, and potential for harm (Table 2). Supporting literature for each item was included in the descriptions in the final list (Table 3). 
Table 1

CFAS Membership Online Survey Demographics

$$
\text { n (\%)* }
$$

\section{Professional Background}

MD

$46(35.7)$

Nurse

$14(10.9)$

Embryologist

$41(31.8)$

Counselor

$8(6.2)$

Administrator

Other

$21(16.3)$

\section{Gender}

Male $36(27.9)$

Female

$92(71.3)$

Prefer not to share

$1(0.8)$

Years Working in Fertility

0-5 years

31 (24.2)

6-10 years

29 (22.7)

11-20 years

29 (22.7)

$>20$ years

39 (30.5)

*Percentages are rounded to one decimal point, therefore, the sum of values in each category may not add to exactly 100. 
Table 2

CFAS National Membership Survey Results for the Top 5 Items

\begin{tabular}{|c|c|c|c|c|c|c|}
\hline Item & $\begin{array}{l}\text { Sum of } \\
\text { Very } \\
\text { Important \& } \\
\text { Moderately } \\
\text { Important } \\
\text { Responses }\end{array}$ & $\begin{array}{l}\text { Issue } \\
\text { Prevalence* }\end{array}$ & Cost* & $\begin{array}{l}\text { Potential } \\
\text { for } \\
\text { Harm* }\end{array}$ & $\begin{array}{l}\text { Aggregate } \\
\text { Score (\%) } \\
\text { of issue } \\
\text { prevalence, } \\
\text { cost, \& } \\
\text { potential } \\
\text { for harm }\end{array}$ & $\begin{array}{l}\text { Recommended } \\
\text { to Include in } \\
\text { Top } 5 \text { List* }\end{array}$ \\
\hline 1. PGT & $54(69.2)$ & $28(50.91)$ & $\begin{array}{l}55 \\
(94.83)\end{array}$ & $\begin{array}{l}42 \\
(73.68)\end{array}$ & 73.1 & $40(69.0)$ \\
\hline $\begin{array}{l}\text { 2. High dose } \\
\text { gonadotropins }\end{array}$ & 49 (64.5) & 39 (70.91) & $\begin{array}{l}42 \\
(76.36)\end{array}$ & $\begin{array}{l}37 \\
(67.27)\end{array}$ & 71.5 & $30(53.6)$ \\
\hline $\begin{array}{l}\text { 3. Assisted } \\
\text { hatching }\end{array}$ & $49(62.8)$ & $34(59.65$ & $\begin{array}{l}37 \\
(66.07)\end{array}$ & $\begin{array}{l}33 \\
(58.93)\end{array}$ & 61.6 & $29(51.8)$ \\
\hline $\begin{array}{l}\text { 4. Immune } \\
\text { therapy }\end{array}$ & $52(67.5)$ & $17(30.36)$ & $\begin{array}{l}43 \\
(78.18)\end{array}$ & $\begin{array}{l}43 \\
(75.44)\end{array}$ & 61.3 & $37(66.1)$ \\
\hline $\begin{array}{l}\text { 5. DNA } \\
\text { fragmentation }\end{array}$ & 54 (68.4) & $30(54.55)$ & $\begin{array}{l}46 \\
(85.19)\end{array}$ & $\begin{array}{l}13 \\
(24.07)\end{array}$ & 54.6 & $31(54.4)$ \\
\hline
\end{tabular}

Table 3

Final Recommendations List

\begin{tabular}{|ll|}
\hline $\begin{array}{l}\text { Recommendation } \\
\text { Number }\end{array}$ & Recommendation \\
\hline 1 & $\begin{array}{l}\text { Don't routinely perform preimplantation genetic testing for aneuploidy screening } \\
\text { on patients undergoing IVF }\end{array}$ \\
\hline 3 & $\begin{array}{l}\text { Don't prescribe gonadotropins in doses of over } 450 \text { units daily for controlled } \\
\text { ovarian stimulation in IVF }\end{array}$ \\
\hline 4 & $\begin{array}{l}\text { Don't routinely perform laser-assisted hatching on fresh embryos prior to } \\
\text { transfer }\end{array}$ \\
\hline 5 & $\begin{array}{l}\text { Don't prescribe corticosteroids, IVIG, leukemia inhibitory factor, or lymphocyte } \\
\text { immunization therapy for patients undergoing IVF, those with a history of } \\
\text { recurrent implantation failure, or those with recurrent pregnancy loss }\end{array}$ \\
\hline
\end{tabular}


Recommendation \#1: Don't routinely perform preimplantation genetic testing for aneuploidy screening on patients undergoing IVF.

Aneuploidy is a well-established cause of implantation failure, miscarriage, and pregnancy anomalies, and is known to increase in frequency with advancing oocyte age [10-12]. Pre-implantation genetic testing for aneuploidy (PGT-A) was developed to select euploid embryos for transfer with the goal of increasing live birth rate [13]. Despite its common use in Canada and the United States, there are several randomized control trials (RCTs) looking at PGT-A using blastocyst biopsy with no clear evidence of benefit [14]. One study comparing single euploid embryo transfer with untested blastocyst transfer demonstrated no statistically significant difference in ongoing pregnancy rate when fresh and first frozen embryo transfer cycle were included in the analysis [15]. Likewise, an RCT comparing single euploid transfer with double embryo transfer of untested embryos showed no difference in live birth rate [16, 17]. While a higher live birth rate was demonstrated in one study of patients randomized to receive either a double euploid embryo transfer or a double untested embryo transfer, this study has been questioned for its applicability because double embryo transfer is not the standard practice in Canada due to the increased risk of multiple gestation [18]. Similarly, in patients with recurrent pregnancy loss (RPL), there are no RCTs demonstrating a benefit of in vitro fertilization (IVF) with PGT-A compared with spontaneous conception, and in fact there may be an increase in time to pregnancy [13].

In summary, while PGT-A may be an appropriate choice for select patients who are counselled on the indications, limitations, and risks, it should not be recommended routinely to all patients. In addition to there being no clear benefit of routine PGT-A, there are also potential harms including risk of false positive findings and embryo loss, as well as additional costs and increased time spent waiting for results [13, 14].

Recommendation \#2: Don't prescribe gonadotropins in doses of over 450 units daily for controlled ovarian stimulation in IVF.

High doses of gonadotropins during IVF has significant potential for harm without evidence of benefit. Ovarian Hyperstimulation Syndrome (OHSS) is a well-known potential harm of high-dose gonadotropin stimulation with the potential for life-threatening complications in severe forms $[19,20]$. An RCT from 2007 of patients under the age of 38 was terminated prematurely when an interim analysis demonstrated a lower embryo aneuploidy rate in patients with lower-dose stimulation (150 units daily) compared with higher-dose stimulation (225 units daily), with a similar number of chromosomally normal embryos created despite fewer oocytes retrieved, and a similar pregnancy rate per cycle start [21]. In a retrospective population-based study of 77,956 IVF cycles and 36,270 consecutive transfers from frozen/thawed embryos, the live birth rate in fresh IVF cycles improved as the number of eggs retrieved increased up to 11 oocytes, at which point the live birth rate plateaued around 30\% [22]. When this same study included analysis of both fresh and frozen embryo transfers, the cumulative live birth rate increased per oocyte retrieved up to approximately 20 eggs where it plateaued at $45.8 \%$; however, the incidence of severe OHSS increased significantly by the number of oocytes, particularly if more than 18 oocytes were retrieved [22]. 
While thromboembolic events were rare, a total of 16 events in 14 patients were observed, and occurred only when 15 or more eggs were retrieved [22].

Other potential risks of high-dose gonadotropin stimulation in pregnancies achieved through IVF with fresh embryo transfer is an association with higher rates of small for gestational age and low birth weight neonates in those with high estradiol levels in the late follicular phase [20]. In summary, balancing the limited benefits of obtaining a high number of oocytes with the increasing risk of OHSS as gonadotropin doses increase, gonadotropins should not be prescribed over 450 units daily.

Recommendation \#3: Don't routinely perform laser-assisted hatching on fresh embryos prior to transfer.

Laser-assisted hatching $(\mathrm{AH})$ is a process by which the zona pellucida of the embryo is breached or thinned out prior to transfer with the goal of facilitating improved embryo expansion for increased pregnancy rates [23]. Risks of AH include embryo injury, unknown effects on fetal and childhood development and disease, and increased rates of monozygotic twinning [24]. A 2012 Cochrane Review of AH looked at 31 trials including 1,992 clinical pregnancies in 5,728 patients [23]. They demonstrated a slightly improved pregnancy rate with AH in analysis of all 31 trials, but when only the 9 RCTs that included information on live birth rate were analyzed, there was no significant difference in rates of clinical pregnancy or live birth [23]. Since this analysis, there have been prospective clinical trials demonstrating no benefit to $\mathrm{AH}$ in those undergoing fresh embryo transfer for advanced reproductive age (35-42 years old), male factor infertility, and endometriosis [25-27]. Furthermore, the National Institute of Clinical Excellence (NICE) guidelines recommend against AH because it has not been proven to increase pregnancy rates [28]. Given a paucity of literature indicating a clear benefit of AH for fresh embryo transfer, in addition to the potential risks and increased costs, it should not be routinely applied.

Recommendation \#4: Don't prescribe corticosteroids, IVIG, leukemia inhibitory factor, or lymphocyte immunization therapy for patients undergoing IVF, those with a history of recurrent implantation failure, or those with recurrent pregnancy loss.

There is a lack of convincing evidence that immunological medications improve pregnancy rates, and there are significant potential side effects. While there is biological plausibility behind the theory that suppressing the immune system can improve outcomes for patients with a history of implantation failure or RPL, meta-analyses have failed to demonstrate improvement in pregnancy or live birth rate with the use of steroids, granulocyte colony-stimulating factor, leukemia inhibitory factor, or immunoglobulin in those undergoing IVF $[29,30]$. Additionally, there is potential for harm, as these immunosuppressive medications may lead to a host of possible side effects including increased susceptibility to infection, venous thromboembolism, and fracture, and often pose added financial strain [31]. For patients with RPL, the literature is more conflicting with a few small studies showing there may be some benefit with specific immune therapies; larger clinical trials exploring the impact on live birth rate are needed to demonstrate effectiveness before these medications are routinely offered [30]. In the context of RPL, the recommendation is to avoid IVIG and lymphocyte immune therapy, where the literature clearly demonstrates a lack of benefit of these medications [30]. Given the absence of clear evidence supporting 
immunological therapies in improving pregnancy rates across a variety of patient contexts in addition to the aforementioned potential side effects, these medications should not be prescribed outside of a research setting.

Recommendation \#5: Don't routinely perform sperm DNA fragmentation testing.

Sperm DNA fragmentation testing is a commonly performed test for which abnormal results have been associated with lower fertilization and pregnancy rates, poorer embryo quality, and higher miscarriage rates [32]. Despite these associations, abnormal results often do not lead to a change in management [32]. Various testing methods for sperm DNA fragmentation exist with inconsistent cut-off values for abnormal results, making evaluation of the literature difficult to generalize; furthermore, there are no studies in which the rate of spontaneous conception is compared with the rate of conception after assisted reproductive therapy (ART) in those with high DNA fragmentation. Sperm DNA fragmentation testing has been traditionally recommended for many indications including for patients with varicocele and abnormal semen parameters, unexplained infertility, RPL, intrauterine insemination (IUI) failure, and IVF or intracytoplasmic sperm injection (ICSI) failure [33]. In a meta-analysis of 30 studies on pregnancy rates associated with sperm DNA fragmentation testing in patients undergoing IVF with ICSI, regression analysis revealed little predictive value for the tests included in the studies (including Sperm Chromatin Structure Assay, TUNEL, and Comet assay) in terms of predicting pregnancy outcomes [32]. In summary, based on a paucity of evidence supporting the clinical application of sperm DNA fragmentation testing, it should not be routinely applied.

\section{Discussion}

We used a rigorous Delphi process to achieve consensus on the controversial and challenging topic of unnecessary and unproven fertility investigations and treatments in Canada. Our recommendations list is designed to initiate conversations between clinicians and patients about resource stewardship, and also to raise awareness amongst clinicians in our specialty about the potential harms of unnecessary care. This list represents consensus through a national multidisciplinary society across clinician groups (e.g. physicians, nurses, embryologists) and other professionals involved in fertility care (e.g. lawyers, counselors). We purposely engaged members of allied health in this process because of their significant influence on fertility treatment decisions, including around the application of treatment add-ons in IVF. Of particular note, this manuscript was written during the COVID-19 global pandemic, which adds another layer of importance to conversations around resource stewardship [34]. There is certainly a pressing need to reshape the delivery of fertility care to reduce the risk of harms posed by potential virus exposure from unnecessary in-person clinical encounters [35].

There are important ethical considerations in the provision of fertility care in Canada, particularly given the combination of public and private funding in Canadian fertility care and elsewhere. Supporters of IVF add-ons argue that offering unproven technologies with biological plausibility to improve the chance of conception respects patient autonomy and expands patient choice [36, 37]. Conversely, autonomy must 
be balanced with the professional responsibility to provide treatments that are effective and evidencebased, and to avoid those of questionable safety with potential harms [38]. Some ethicists and clinicians furthermore argue that new fertility therapies should undergo thorough investigation starting from hypothesis-driven basic research, to testing on donated human embryos and/or performing clinical trials prior to adoption into clinical practice [37]. It is arguable that voluntary informed consent, in which patients must understand the risks and benefits of proceeding with an intervention, is not truly possible for investigations or treatments in which there is insufficient evidence on clinical effectiveness and safety $[37,39]$. Additional potential downsides to providing patients with options for unproven therapies include increased cost, creation of false hope, risk of harm to patients or embryos, and risk for the intervention to hinder or delay patients in achieving pregnancy. In the foregoing examples, resource stewardship principles should be balanced with considerations of patient autonomy and choice.

More research is needed around the use of fertility add-ons, as well as patient attitudes towards them. A survey of patients at fertility clinics in the United Kingdom (UK) found that $74 \%$ of respondents had used at least one fertility treatment add-on, a rate that has increased over time, and that the use of add-ons was associated with privately funded care [40]. Supporting the reasoning behind creating our recommendations list, in 2019, the UK's Human Fertilisation and Embryology Authority (HFEA) created a consensus statement on criteria for the responsible use of fertility treatment add-ons, based on the principle: "Where there is no evidence to support safety and efficacy, treatment add-ons should only be offered to patients in a research setting with sound methodology and approval from a research ethics committee" [41]. Similar to our list, HFEA includes assisted hatching, pre-implantation genetic testing, and reproductive immunology tests and treatments in their traffic light system cautioning patients against the use of these add-ons for a lack of supporting evidence [41]. Interestingly, the American Choosing Wisely list for REI has little overlap with our final recommendations list, with a particular focus on investigations to question, rather than treatments, which potentially relates to our differing healthcare systems [7].

Limitations of creating this list through a modified Delphi approach include the difficulty in staying abreast of the ever-evolving literature during the process, requiring recognition that with development of new technologies we will need to incorporate new recommendations or change recommendations over time. CWC requires societies to review lists annually, however given resource and time constraints, these reviews do not require applying the Delphi approach each time. During list development, there were challenges relating to regional variations in practice across the country (e.g. PGT-A is performed at high rates in some jurisdictions, and seldomly in others). Significant resistance to including some items on the list was received by some fertility physicians due to the concern that physicians would be unable to offer interventions on the list, even if felt to be clinically justified. This, however, is not the intention of the recommendations nor the framing of the CWC campaign. It is important that in addition to promoting our list, that we also educate around the focus of the campaign, which is to identify tests, treatments, and procedures that are not evidence-based and can pose potential harms, in order to raise awareness and spark meaningful conversation between clinicians and patients. Future goals of this project include promoting the widespread implementation of the CWC list, followed by an evaluation of the impact of these recommendations on clinical practice.

Page $10 / 15$ 


\section{Declarations}

\section{Funding}

This work was supported by the CFAS who funded the in-person Working Group Meeting, CFAS membership survey distribution and translational services.

\section{Competing Interests}

CA Jones is the program director for the gynecologic reproductive endocrinology and infertility fellowship at the University of Toronto, which receives payments from EMD Serono Canada and Ferring Canada to support fellowship academic endeavors. L Hawkins has no relevant competing interests to declare. CL Friedman has non-financial roles acting as a resident member of the Society of Obstetrician and Gynaecologists of Canada Choosing Wisely Canada committee and the Choosing Wisely Canada Students and Trainees Advocating for Resource Stewardship (STARS) program. J Hitkari acts as a board member of the CFAS. E McMahon has received consulting fees from two sources in 2019: EMD Serono to provide input for a fertility nurse education module series, and Merck to provide input for a nurse education model on bereavement. E McMahon has also received a travel award from EMD Serono in 2019. E McMahon has acted as a board member of the CFAS from 2016 to 2019, as well as the president of CFAS from 2019 to 2021. K Born is the knowledge translation lead for Choosing Wisely Canada, which is a full-time salaried position funded through Health Canada.

\section{Author Contributions}

CA Jones, L Hawkins, J Hitkari, E McMahon, and K Born contributed to the study conception and design, and data collection. All authors participated in material preparation, data analysis, and manuscript writing, and editing. All authors read and approved the final manuscript.

1. C.A. Jones, MD, FRSCS: protocol development, data collection, data analysis, manuscript writing \& editing.

2. L. Hawkins, MD, FRCSC: protocol development, data collection, data analysis, manuscript writing \& editing.

3. C.L. Friedman, MD, BScN, HBSc: data analysis, manuscript writing \& editing.

4. J. Hitkari MD, FRCSC: protocol development, data collection, data analysis, manuscript writing \& editing.

5. E. McMahon, RNEC, MN: protocol development, data collection, data analysis, manuscript writing \& editing.

6. K.B. Born, MSc, PhD: protocol development, data collection, data analysis, manuscript writing \& editing.

\section{Ethics and Consent}


This is an observational study that did not require ethical approval. Informed consent was obtained from all individual participants included in the study.

\section{Acknowledgements}

The authors would like to thank the members of the Canadian Fertility and Andrology Society (CFAS) Choosing Wisely Working Group: Heather Cockwell, Jennifer Hilton, Bryden Magee, Rhonda Zwingerman, Gillian Graves, Pat Chronis-Brown and Lynda Hughes.

\section{References}

1. Kawwass JF, Penzias AS, Adashi EY. Fertility-a human right worthy of mandated insurance coverage: the evolution, limitations, and future of access to care. Fertil Steril. 2021 Jan;115(1):29-42. https://doi.org/10.1016/j.fertnstert.2020.09.155

2. Mahboob T. No National Plan for Fertility Treatment Remains Challenge for Canadians Hoping to Conceive. Canadian Broadcasting Corporation. January 2, 2020.

3. Blakely B, Williams J, Mayes C, Kerridge I, Lipworth W. Conflicts of interest in Australia's IVF industry: an empirical analysis and call for action. Hum Fertil (Camb). 2019 Dec;22(4):230-237. https://doi.org/10.1080/14647273.2017.1390266

4. Heneghan C, Spencer EA, Bobrovitz N, Collins DR, Nunan D, Plüddemann A, Gbinigie OA, Onakpoya I, O'Sullivan J, Rollinson A, Tompson A, Goldacre B, Mahtani KR. Lack of evidence for interventions offered in UK fertility centres. BMJ. 2016 Nov 27;355:i6295. https://doi.org/10.1136/bmj.i6295

5. Born K, Kool T, Levinson W. Reducing overuse in healthcare: advancing Choosing Wisely. BMJ. 2019 Nov 5;367:16317. https://doi.org/10.1136/bmj.16317

6. Born K, Huynh T, Levinson W. Reflecting on Choosing Wisely Canada at Five Years: Accomplishments, Challenges and Opportunities for Reducing Overuse and Improving Quality. Healthcare Papers. 2019 July:9-17.

7. American Society for Reproductive Medicine. Ten Things Physicians and Patients Should Question. 2019. Available at: https://www.choosingwisely.org/societies/american- society-for-reproductivemedicine/. Accessed May 28, 2021.

8. Linstone HA, Turoff M. The Delphi Method: Techniques and Applications. Massachusetts: AddisonWesley Educational Publishers Inc., 1975.

9. Green CR, Blake JM, Carson GD, Po L, Brown ARH, Friedman CL. Choosing Wisely: SOGC's Top 10 Recommendations. J Obstet Gynaecol Can. 2018 Jun;40(6):716-722. https://doi.org/10.1016/j.jogc.2018.04.024

10. Munne S, Lee A, Rosenwaks Z, Grifo J, Cohen J. Diagnosis of major chromosome aneuploidies in human preimplantation embryos. Hum Reprod. 1993 Dec;8(12):2185-91. https://doi.org/10.1093/oxfordjournals.humrep.a138001 
11. Hassold T, Chen N, Funkhouser J, Jooss T, Manuel B, Matsuura J, Matsuyama A, Wilson C, Yamane JA, Jacobs PA. A cytogenetic study of 1000 spontaneous abortions. Ann Hum Genet. 1980 Oct;44(2):151-78. https://doi.org/10.1111/j.1469-1809.1980.tb00955.x

12. Sauer MV, Paulson RJ, Lobo RA. Reversing the natural decline in human fertility. An extended clinical trial of oocyte donation to women of advanced reproductive age. JAMA. 1992 Sep 9;268(10):1275-9. https://doi.org/10.1001/jama.268.10.1275

13. Murugappan G, Shahine LK, Perfetto CO, Hickok LR, Lathi RB. Intent to treat analysis of in vitro fertilization and preimplantation genetic screening versus expectant management in patients with recurrent pregnancy loss. Hum Reprod. 2016 Aug;31(8):1668-74.

https://doi.org/10.1093/humrep/dew135

14. Munné S, Kaplan B, Frattarelli JL, Child T, Nakhuda G, Shamma FN, Silverberg K, Kalista T, Handyside AH, Katz-Jaffe M, Wells D, Gordon T, Stock-Myer S, Willman S. Preimplantation genetic testing for aneuploidy versus morphology as selection criteria for single frozen-thawed embryo transfer in goodprognosis patients: a multicenter randomized clinical trial. Fertil Steril. 2019 Dec;112(6):10711079.e7. https://doi.org/10.1016/j.fertnstert.2019.07.1346

15. Yang Z, Salem SA, Liu X, Kuang Y, Salem RD, Liu J. Selection of euploid blastocysts for cryopreservation with array comparative genomic hybridization $(\mathrm{aCGH})$ results in increased implantation rates in subsequent frozen and thawed embryo transfer cycles. Mol Cytogenet. 2013 Aug 9;6(1):32. https://doi.org/10.1186/1755-8166-6-32

16. Forman EJ, Hong KH, Ferry KM, Tao X, Taylor D, Levy B, Treff NR, Scott RT Jr. In vitro fertilization with single euploid blastocyst transfer: a randomized controlled trial. Fertil Steril. 2013 Jul;100(1):1007.e1. https://doi.org/10.1016/j.fertnstert.2013.02.056

17. Forman EJ, Hong KH, Franasiak JM, Scott RT Jr. Obstetrical and neonatal outcomes from the BEST Trial: single embryo transfer with aneuploidy screening improves outcomes after in vitro fertilization without compromising delivery rates. Am J Obstet Gynecol. 2014 Feb;210(2):157.e1-6. https://doi.org/10.1016/j.ajog.2013.10.016

18. Scott RT Jr, Upham KM, Forman EJ, Hong KH, Scott KL, Taylor D, Tao X, Treff NR. Blastocyst biopsy with comprehensive chromosome screening and fresh embryo transfer significantly increases in vitro fertilization implantation and delivery rates: a randomized controlled trial. Fertil Steril. 2013 Sep;100(3):697-703. https://doi.org/10.1016/j.fertnstert.2013.04.035

19. Practice Committee of the American Society for Reproductive Medicine. Prevention and treatment of moderate and severe ovarian hyperstimulation syndrome: a guideline. Fertil Steril. 2016 Dec;106(7):1634-1647. https://doi.org/10.1016/j.fertnstert.2016.08.048

20. Blumenfeld Z. Why more is less and less is more when it comes to ovarian stimulation. $J$ Assist Reprod Genet. 2015 Dec;32(12):1713-9. https://doi.org/10.1007/s10815-015-0599-7

21. Baart EB, Martini E, Eijkemans MJ, Van Opstal D, Beckers NG, Verhoeff A, Macklon NS, Fauser BC. Milder ovarian stimulation for in-vitro fertilization reduces aneuploidy in the human preimplantation 
embryo: a randomized controlled trial. Hum Reprod. 2007 Apr;22(4):980-8.

https://doi.org/10.1093/humrep/del484

22. Magnusson $\AA$, Källen K, Thurin-Kjellberg A, Bergh C. The number of oocytes retrieved during IVF: a balance between efficacy and safety. Hum Reprod. 2018 Jan 1;33(1):58-64.

https://doi.org/10.1093/humrep/dex334

23. Carney SK, Das S, Blake D, Farquhar C, Seif MM, Nelson L. Assisted hatching on assisted conception (in vitro fertilisation (IVF) and intracytoplasmic sperm injection (ICSI). Cochrane Database Syst Rev. 2012 Dec 12;12(12):CD001894. https://doi.org/10.1002/14651858.cd001894.pub5

24. Practice Committee of the American Society for Reproductive Medicine; Practice Committee of the Society for Assisted Reproductive Technology. Role of assisted hatching in in vitro fertilization: a guideline. Fertil Steril. 2014 Aug;102(2):348-51. https://doi.org/10.1016/j.fertnstert.2014.05.034

25. Shi W, Hongwei T, Zhang W, Li N, Li M, Li W, Shi J. A Prospective Randomized Controlled Study of Laser-Assisted Hatching on the Outcome of First Fresh IVF-ET Cycle in Advanced Age Women. Reprod Sci. 2016 Oct;23(10):1397-401. https://doi.org/10.1177/1933719116641764

26. Razi MH, Halvaei I, Razi Y. Laser assisted zona hatching does not improve live birth rate in patients undergoing their first ICSI cycles. Iran J Reprod Med. 2013 Dec;11(12):1021-6. http://www.ncbi.nlm.nih.gov/pmc/articles/pmc3941401/

27. Nada AM, El-Noury A, Al-Inany H, Bibars M, Taha T, Salama S, Hassan F, Zein E. Effect of laserassisted zona thinning, during assisted reproduction, on pregnancy outcome in women with endometriosis: randomized controlled trial. Arch Gynecol Obstet. 2018 Feb;297(2):521-528. https://doi.org/10.1007/s00404-017-4604-5

28. National Institute for Health and Care Excellence. Fertility Problems: assessment and treatment. Clinical guideline. September 6, 2017. Accessible at: https://www.nice.org.uk/guidance/cg156. Accessed May 28, 2021.

29. Boomsma CM, Keay SD, Macklon NS. Peri-implantation glucocorticoid administration for assisted reproductive technology cycles. Cochrane Database Syst Rev. 2012 Jun 13;(6):CD005996. https://doi.org/10.1002/14651858.cd005996.pub3

30. Achilli C, Duran-Retamal M, Saab W, Serhal P, Seshadri S. The role of immunotherapy in in vitro fertilization and recurrent pregnancy loss: a systematic review and meta-analysis. Fertil Steril. 2018 Nov;110(6):1089-1100. https://doi.org/10.1016/j.fertnstert.2018.07.004

31. Waljee AK, Rogers MA, Lin P, Singal AG, Stein JD, Marks RM, Ayanian JZ, Nallamothu BK. Short term use of oral corticosteroids and related harms among adults in the United States: population based cohort study. BMJ. 2017 Apr 12;357:j1415. https://doi.org/10.1136/bmj.j1415

32. Agarwal A, Cho CL, Majzoub A, Esteves SC. The Society for Translational Medicine: clinical practice guidelines for sperm DNA fragmentation testing in male infertility. Transl Androl Urol. 2017 Sep;6(Suppl 4):S720-S733. https://doi.org/10.21037/tau.2017.08.06

33. Cissen M, Wely MV, Scholten I, Mansell S, Bruin JP, Mol BW, Braat D, Repping S, Hamer G. Measuring Sperm DNA Fragmentation and Clinical Outcomes of Medically Assisted Reproduction: A Systematic 
Review and Meta-Analysis. PLoS One. 2016 Nov 10;11(11):e0165125.

https://doi.org/10.1371/journal.pone.0165125

34. Bhatia RS, Shojania KG, Levinson W. Cost of contact: redesigning healthcare in the age of COVID. BMJ Qual Saf. 2021 Mar;30(3):236-239. https://doi.org/10.1136/bmjqs-2020-011624

35. Madjunkov M, Dviri M, Librach C. A comprehensive review of the impact of COVID-19 on human reproductive biology, assisted reproduction care and pregnancy: a Canadian perspective. J Ovarian Res. 2020 Nov 27;13(1):140. https://doi.org/10.1186/s13048-020-00737-1

36. Harper J, Jackson E, Sermon K, Aitken RJ, Harbottle S, Mocanu E, Hardarson T, Mathur R, Viville S, Vail A, Lundin K. Adjuncts in the IVF laboratory: where is the evidence for 'add-on' interventions? Hum Reprod. 2017 Mar 1;32(3):485-491. https://doi.org/10.1093/humrep/dex004

37. Wilkinson J, Malpas P, Hammarberg K, Mahoney Tsigdinos P, Lensen S, Jackson E, Harper J, Mol BW. Do à la carte menus serve infertility patients? The ethics and regulation of in vitro fertility add-ons. Fertil Steril. 2019 Dec;112(6):973-977. https://doi.org/10.1016/j.fertnstert.2019.09.028

38. Dondorp W, de Wert G. Innovative reproductive technologies: risks and responsibilities. Hum Reprod. 2011 Jul;26(7):1604-8. https://doi.org/10.1093/humrep/der112

39. Madeira JL, Coyne K, Jaeger AS, Parry JP, Lindheim SR. Inform and consent: more than just "sign here". Fertil Steril. 2017 Jul;108(1):40-41. https://doi.org/10.1016/j.fertnstert.2017.03.022

40. Spencer EA, Mahtani KR, Goldacre B, Heneghan C. Claims for fertility interventions: a systematic assessment of statements on UK fertility centre websites. BMJ Open. 2016 Nov 27;6(11):e013940. https://doi.org/10.1136/bmjopen-2016-013940

41. Human Fertilisation \& Embryology Authority. Treatment add-ons with limited evidence. 2020. Available at: https://www.hfea.gov.uk/treatments/treatment-add-ons/. Accessed May 28, 2021.

\section{Figures}

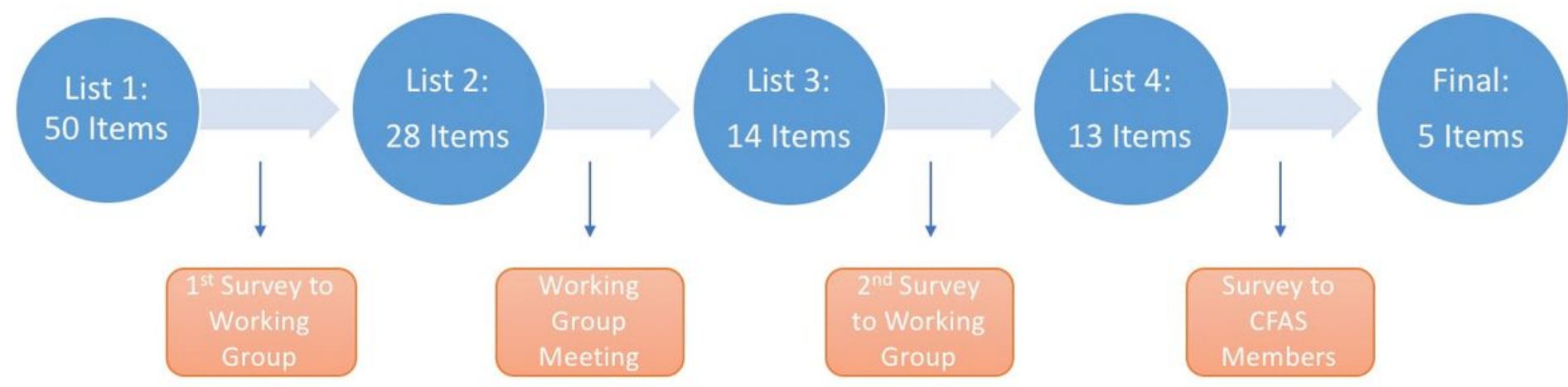

\section{Figure 1}

Flow diagram of the modified Delphi consensus approach. Graphic created using Microsoft PowerPoint. 